\title{
Co-Existence of Hereditary Pyrimidine 5'-Nucleotidase Deficiency and Heterozygous $\alpha$-Thalassemia: A Case Presentation
}

\author{
Kalıtsal Pirimidin 5'- Nükleotidaz Eksikliği ve Alfa Talasemi \\ Taşıyıcı Birlikteliği: Olgu Sunumu
}

\author{
A. Agapidou ${ }^{1}$, S. Theodoridou ${ }^{1}$, K. Tegos ${ }^{3}$, E. Mandala $^{4}$, E. Leukou ${ }^{1}$, O. Karakasidou ${ }^{1}$, \\ B. Aletra ${ }^{1}$, A. Sevastidou ${ }^{1}$, M. Alemayehou ${ }^{1}$, E. Voskaridou ${ }^{2}$ \\ ${ }^{1}$ Hippokration Hospital of Thessaloniki, Hemoglobinopathy Prevention Unit, Thessaloniki, Greece \\ ${ }^{2}$ Laikon Hospital of Athens, Thalassemia Center, Athens, Greece \\ ${ }^{3}$ NIMITS, Military Hospital, Athens, Greece \\ ${ }^{4}$ Aristotelion University of Thessaloniki, 4th Unit of Internal Medicine, Thessaloniki, Greece
}

\section{To the Editor,}

Pyrimidine 5'-nucleotidase (P5N) is an intra-erythrocytic isoenzyme that catalyzes the dephosphorylation of pyrimidine ribonucleotides, which are the product of DNA catabolism. A reduction in $\mathrm{P} 5 \mathrm{~N}$ reactivity leads to accumulation of pyrimidine products in erythrocytes, which increases its life span, resulting in hemolytic anemia and intense basophilic stippling [1].

P5N deficiency is inherited in an autosomal recessive fashion and is one of the most important causes of inherited non-spherocyte anemia, as well as G-6PD and pyruvate kinase deficiency. P5N deficiency is characterized by hemolytic anemia, splenomegaly, and intense basophilic stippling. There are several reports in the literature concerning reduced $\mathrm{P} 5 \mathrm{~N}$ reactivity in patients with intermediate and heterozygous $\beta$-thalassemia; however, the co-existence of P5N deficiency in a patient with $\alpha$-thalassemia is a rare event $[2,3,4]$.

We report the clinical and hematological findings in a 25-year-old female that was screened for hemoglobinopathies due to her pregnancy ( $6^{\text {th }}$ week). Based on her medical records, she was known to be a carrier of 5PN deficiency. The proposita's hematological parameters were as follows: $\mathrm{Hb}: 10.7 \mathrm{~g} \mathrm{dL}^{-1}$; Hct: 34\%; RBC: $4.35 \times 10^{6}$; MCV: $77 \mathrm{fL}$; MCH: 24.7 pg; RDW: 16.2\%; reticulocytes: 3.97\%; ferritin: 30 (normal range=20-81ngr/Ml). Microscopic examination of a stained peripheral blood smear showed severe anisocytosis, microcytosis, and basophilic stippling. Biochemical analysis of hemoglobin using high-performance liquid chromatography (HPLC) showed normal values for hemoglobin A2 (HbA2: 2.4\%) and hemoglobin F (HbF: $0.5 \%)$. No abnormal hemoglobins were detected.

Due to an unclear hematological picture in the proposita's husband, who was thought to be heterozygous for thalassemia, genetic analysis of the proposita's DNA was performed. Molecular analysis showed that she was heterozygous for the mild mutation of $\alpha$-thalassemia $(-\alpha 3,7 /$ NI). In conclusion, mismatch between the hematological parameters of the presented pregnant patient and the usual hematological phenotype associated with $\alpha$-thalassemia $\left(-\alpha\right.$ 3,7/NI) were due to the lack of P5N (P5N: $1.88 \mathrm{U} \mathrm{g}^{-1}$ of $\mathrm{Hb}$ ). The patient never required blood transfusion. The co-existence of hereditary P5N deficiency and heterozy-

\section{Address for Correspondence: A. AGAPIDOU, M.D.,}

Alexandra Agapidou, Hippokration Hospital of Thessaloniki, Hemoglobinopathy Prevention Unit, Thessaloniki, Greece

Phone: 00302310892819 E-mail: alekagapidou@yahoo.gr

Received/Geliş tarihi : January 26, 2012

Accepted/Kabul tarihi : January 30, 2012 
gous $\alpha$-thalassemia is extremely interesting due to the fact that to the best of our knowledge this is the first report of such a case.

\section{Conflict of Interest Statement}

The authors have no conflicts of interest, including specific financial interests, relationships, and/or affiliations, relevant to the subject matter or materials presented.

\section{References}

1. Evdokia Mandala, Study of Pyrimidine 5- Nucleotide(P5N) Activity In Hereditary Hemoglobinopathies. DoctorateThesis, Thessaloniki 1997.

2. Zerez CR, Lachant NA, Lent KM, Tanaka KR. Decreased pyrimidine nucleoside monophosphate kinase activity in sickle erythrocytes. Blood 1992; 80:512-516.

3. David O, Sacchetti L, Vota MG, Comino L, Perugini L, Pescarmona GP. Pyrimidine 5'-nucleotidase and oxidative damage in red blood cells transfused to beta-thalassemic children. Haematologica 1990; 75:313-318.

4. Dell'Edera D, Malvasi A, Tinelli A, Mazzone E, Leo M, Monti $\mathrm{V}$, Epifania AA. Importance of the molecular diagnosis in the screening of alpha-thalassemia. Recenti Prog Med 2011; 102(7-8):302-306. doi: 10.1701/913.10050. Italian. 